\title{
Occupational Pattern and Income Inequality in A Sichuan Village
}

PETER FENGER, STEEN FOLKE, ALLAN JØRGENSEN, PETER MILTHERS and OLE ODGAARD

The rural reforms in China have brought substantial increases in income in the last decade. Much attention has been paid to the local high-income groups of specialized households. But very few case studies give a more detailed picture of the local income differentiation. The variety of occupations among the households and the corresponding distribution of incomes are rarely described in detail. The crucial issue of requirements necessary, in terms of labour, capital, political power and "guanxi«, has not been thoroughly discussed. Only few attempts have been made to conceptualize the pattern of different types of inequality and their possible impact on future development related to socialist goals.

This is generally acknowledged in the research community, but the obstacles in obtaining the relevant basic information have been numerous. Official permissions, a long lasting field-study and sheer luck need to coincide.

We succeeded in surmounting some of these obstacles. This article is not based on a long lasting field-study, but presents some conclusions from a base-line survey. Nevertheless, we think that the collection of rather detailed information from a Sichuan village may delineate some relations between occupational pattern and income inequality. The article further aims to shed light on the requirements necessary to enter the high-income activities. A theoretical attempt to conceptualize the different types of inequality will be presented in order to generalize the impact on future class formation and socialist development. It is our hope, that this may serve as an initial step to broaden the ongoing debate on rural income distribution.

\section{Introduction}

This article is based on a stay in Xin Cun village in Sichuan province during most of the month of March 1988. The participants of the field work were organized in four groups, dealing with agriculture, village industry, family 
and womens issues and organization and decision making. All groups carried out numerous interviews with village leaders and ordinary villagers, using formal questionnaires as well as informal checklists. All interviews were undertaken without accompanying officials, and no questionnaires were subject to official approval. Important knowledge was acquired when accomodated in the private homes of villagers, who patiently answered our innumerable questions.

We have chosen to concentrate on the occupation and income situation, as we succeeded in obtaining detailed quantitative data on these issues for each and every household in the village.

We are aware of the question of reliability. The data material is not without lacunae and inconsistencies, and some of these will be discussed in this presentation. However, we have no reason to believe that this detailed statistical material, obtained from the village authorities, should not be authentic and, generally speaking, correct. The interviews we conducted with numerous families both confirmed the overall validity and revealed some minor discrepancies.

\section{Xin Cun}

The village Xin Cun is located in Jinma township, Wenjiang county about $50 \mathrm{~km}$. west of Chengdu, the capital of Sichuan. The village borders Jinma river and the whole area forms part of a very fertile plain irrigated by the Dujiangyan complex.

In 1987 the population of the village was 1377, consisting of 320 families. Most families were of middle size, 4-6 persons, usually consisting of 3 generations. The distribution according to sex is very even, and the age distribution is as follows: $0-18$ years: $25 \%, 18-60$ years: $65 \%$, above 60 years: $10 \%$. Thus the proportion of people below 18 years of age is significantly lower, about half, than that of the national average probably due to a strict adherence to the one-child policy.

Naturally, the fact that foreigners are allowed to stay in the village raises questions. Is it a showpiece ? Yes and no. Yes, because foreigners had visited the village previously (although we were the first group that had stayed for longer than two days), and because it is above average in terms of living standards. This is especially due to very high crop-yields and extensive pig-rearing. No, on the other hand, because it is not at all atypical by other parameters. The village is not all that different from scores of other 
villages in the region. The village economy is fairly typical for the county with its emphasis on agriculture (the main crops being the same as everywhere) and animal husbandry. The village industries are, however, slightly less developed than in the neighbouring villages although they equal the average level for all-China.

This brings us to the next obvious question: How representative is Xin Cun for the villages of Sichuan or China ? It is certainly not average in terms of income. The per capita income of Xin Cun (806 Yuan in 1987) is substantially higher than that of the county (595 Yuan) in which it is located - not to mention China (463 Yuan). The entire region is a very fertile and productive agricultural area and this certainly applies to Xin Cun.

Scarcity of land is a fundamental condition in this village as in most other villages. The total area of arable land in Xin Cun is just about 85.4 ha. This means that each person (including children) can get a tiny plot of 0.06 ha., which is about half the average size per person in China. Outside the most busy seasons one worker easily can manage the land of 5 persons.

In order to make up for the limited land the cultivation is intensive. The entire area is under irrigation and both organic manure and chemical fertilizer are being applied in heavy doses. As shown in Table 1 the yields of rice and wheat are well above the average in China.

\section{Table 1. Yield of Main Crops in Jinma Township}

\begin{tabular}{lccc} 
Ton per ha. & 1978 & 1987 & Growth \\
\hline Rice & $6.04(3.98)$ & $7.37(5.42)$ & $22 \%(36 \%)$ \\
Wheat & $4.21(1.85)$ & $5.12(3.05)$ & $22 \%(65 \%)$ \\
Rape seed & $2.09(0.72)$ & $2.46(2.90)$ & $18 \%(302 \%)$ \\
\hline
\end{tabular}

The figures in brackets are the all-China averages

Sources: Jinma Agricultural extension Center (Jinma figures), Zhongguo Tongji Zhaiyao - 1988 (Beijing: Zhongguo Tongji Chubanshe, 1988), p. 25-28 (All-China figures).

The fact that the increase in yields has been less impressive here than elsewhere has to be viewed against the background that in the late 1970s yields in this region were much higher than in other parts of China. In 1987 the total output of grain was 800 tons out of which 140 were sold to the state. The gross output value of agriculture was 1.06 mill. Yuan, which is 770 Yuan per capita - or $41 \%$ higher than the national average rural per capita figure. ${ }^{1}$

The extensive size of rural surplus labour has made possible an inten- 
sification of other economic activities. Animal husbandry is important in Xin Cun, particularly pig rearing. The average number of pigs per family is higher than 6 - compared to 1.6 for China as a whole. ${ }^{2}$

There are 18 specialized households in the village, mainly engaged in crop processing, meat processing, tractor driving, chicken breeding, etc. 15 of these are one family each, and the remaining three have joined in a cooperative sausage factory.

Manufacturing industries play a minor role in Xin Cun, although there are a number of small-scale industrial units. Different types of ownership exist. The first type is the household-based enterprises. Such private or jointfamily enterprises have contributed most to the modest rural enterprise development during the last decade, The second type of rural enterprises is the collectively-owned. The development here has been a change to new, more profitable productions rather than an emergence of new enterprises.

In sum, the development of the last decade has increased the wealth of the already prosperous Xin Cun village. This is clearly indicated in the building boom in the village. According to the village party-secretary only 25 out of 320 households have not rebuilt their homes since the reforms started.

The income from crop-production, animal husbandry and non-farm activities have had quite different effects on the income distribution in Xin Cun. This has been due to the unequal distribution of the requirements that are necessary to develop high-income activities. Economic means, professional skills and market experience have been crucial, but the sociopolitical factors of family network and cadre relations (guanxi) proved equally important. The unequal qualifications among the villagers are not only going to influence the distribution of wealth, but may also have a substantial impact on future class formations and the development related to the concepts of socialism.

\section{Occupation and Income Inequalities in Xin Cun}

A general presentation of the income inequality will be given, before the relations between incomes and requirements are discussed. The statistical information presented has been supplied by local authorities and interviews with authorities and villagers during our stay in the village.

For each of the 320 households information was gathered on family size, demography (sex and age of members), size of landholdings, the crop 
yields of rice, wheat and rape-seed, size and occupation of labour-force (farming, animal husbandry, service, industry, transport etc), size and sources of income, expenses and taxes.

However, some inconsistencies occur due to different periods of time (end-1986 and end-1987 figures). Thus, in a few cases the demographic data on households members and the data on size of labour force vary, and information on occupation does not correlate with the information obtained on the different sources of income. These differences, due to the number of marriages and deaths in the year of 1987, are too infrequent to disturb the general trends analyzed; some inconsistencies have been corrected by means of cross-checks and interviews.

Throughout the article the data of the 320 households will be presented in the following way: The 320 households were ranked into 10 groups of 32 households each, and the criterion used was net-income per capita. Gross-income was used when dividing the total household income into sub-incomes of farming, animal husbandry, industry, construction, service, etc., because the figures of tax and expenses are aggregated and not specified on each source of income. ${ }^{3}$

The aggregation of tax and expenses is unfortunate. It makes it impossible to calculate the net-income for each respective source of income, which would be a better measure than gross income when evaluating income differencies, since the very high incomes are supposed to pay higher taxes. Another shortcoming is that our detailed information is for one year only, namely 1987. It was not obtained for other years making an analysis over time impossible. This is of relevance when evaluating the very high income occupations, where large investments from previous years rightfully ought to be deducted when judging current incomes.

The average income for each of the ten incomegroups is specified into the three main sources of income: crop production, animal husbandry (including fishery and forestry), and non-farm activities (manufacturing industry, service, trade and commerce, construction, transport and other income). Figure 1 shows the earnings of the incomegroups divided into the three main sources of income.

As figure 1 illustrates, the income from crop production is almost the same for all of the ten income groups. All families have gained substantial income increases during the past decade, and there was little difference in the per capita income from farming between the richest and the poorest households. A mere $20 \%$ differentiates the richest and poorest group of 


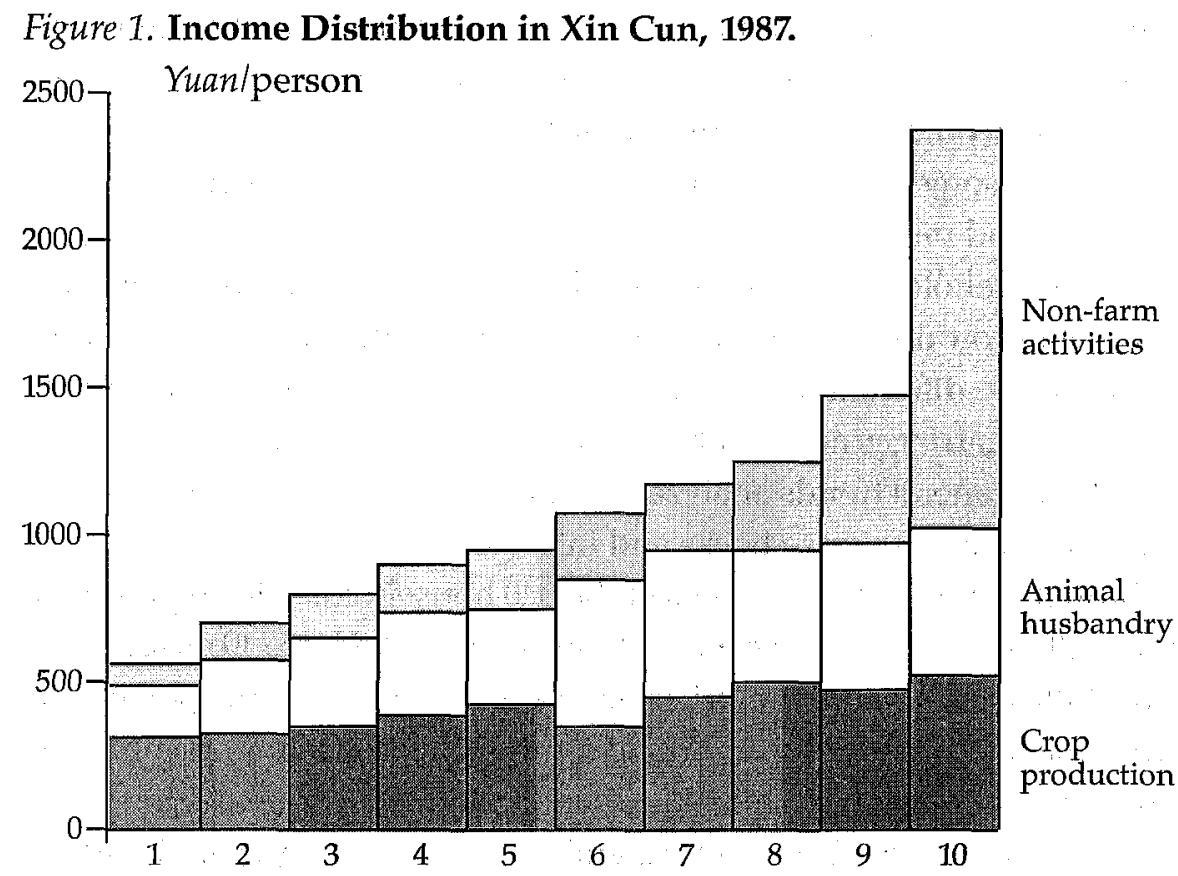

households.

Income differences are largely due to differences in activities outside cropproduction. Thus, the incomes from other activities than cropproduction amount to $42 \%$ for the poorest tenth compared to $80 \%$ for the richest tenth (if calculated for the richest and poorest $5 \%$ of households, the figure would be $38 \%$ and $84 \%$, respectively).

All non-crop incomes increase considerably when moving from group 1 to 10. This is reflected in the income distributional trend of animal husbandry, where the average income ranges from 182 Yuan per capita in the poorest group to 529 Yuan in group 9 (or 514 Yuan in group 10), on the average. Nevertheless, the incomes from animal husbandry constitute as much as $26 \%$ of the total income of the poorest tenth and only $22 \%$ for the richest tenth. This fact reveals the importance of non-farm activities for the richest households.

The non-farm activities (activities outside cropproduction and animal husbandry) show the most distinctive increase of incomes ranging from 70 Yuan per capita for the poorest tenth to 1300 Yuan per capita for the richest tenth. Thus the poorest 32 families received only $12 \%$ of their total income from non-farm activities, while the richest 32 households gained as much as $58 \%$ (the figure for the poorest and richest 16 households - or upper and 
lower $5 \%$ of households - is 3\% and $68 \%$, respectively). All the highest incomes derive from household- based enterprises, whether single or joint family-run.

Fig. 2. Main Source of Income in Xin Cun, 1987.

(10 income groups of 32 households each)

\begin{tabular}{|c|c|r|l|l|l|l|c|c|}
\hline Group & \multicolumn{2}{|l|}{ Farming } & \multicolumn{5}{l|}{ Non-farm activities } \\
\hline & $\begin{array}{c}\text { crop } \\
\text { produc- } \\
\text { tion }\end{array}$ & $\begin{array}{c}\text { animal } \\
\text { husban- } \\
\text { dry }\end{array}$ & industry & trade & service & $\begin{array}{c}\text { construc- } \\
\text { tion }\end{array}$ & $\begin{array}{c}\text { trans- } \\
\text { port }\end{array}$ & other \\
\hline 1 & 30 & 2 & & & & & & \\
\hline 2 & 27 & 4 & & & & 1 & & \\
\hline 3 & 25 & 7 & & & & & & \\
\hline 4 & 20 & 12 & & & & & & \\
\hline 5 & 24 & 8 & & & & & & \\
\hline 6 & 11 & 21 & & & & & & \\
\hline 7 & 13 & 15 & & 1 & 1 & 1 & & 1 \\
\hline 8 & 11 & 14 & 3 & 1 & & 2 & 1 & \\
\hline 9 & 6 & 12 & 3 & 7 & 1 & 1 & 1 & 1 \\
\hline 10 & 3 & 8 & 3 & 5 & 2 & 3 & 8 & \\
\hline Total & 170 & 103 & 9 & 14 & 4 & 8 & 10 & 2 \\
\hline
\end{tabular}

The close correlation between non-farm activities and high incomes is also illustrated in figure 2, where the main incomes ${ }^{4}$ for each of the 320 households are listed.

As shown in the figure, the five lowest income groups (with the exception of one household) all have crop production as the dominating source of income. However, animal husbandry gains increasing importance from group 1 to 5 , and it is the most frequent source of main income in the income-groups 6 to 8 . The non-farm activities become increasingly more important in the very high income-groups. Having the main income from various non-farm activities characterises group 9 and 10, while the single non-farm activity of transportation is the most frequent main income in group 10.

The trend towards specialization increases in the high-income groups. Thus, in group 10 the major part of the households' high incomes derives from a single activity. In the households with manufacturing industry as 
main income this single activity contributed $63 \%$ of the total income. The corresponding figures in transportation and trade are as high as $65 \%$ and $70 \%$. Here we find the so called «wan yuan hu« (10.000 Yuan households).

However, on the average the income from the main occupation only constitutes $50 \%$ of the total income in Xin Cun. Each household engages in several activities. Although the rich households gain most of their income from few activities and the poor households earn little from non-farm activities, this does not indicate that most families engage in few activities. On the contrary all households have a great variety of income-sources, whether the household is rich or poor or have few or many household members. This is illustrated in figure 3.

Fig. 3. The 320 Households in Xin Cun Grouped According to Number of Income Sources and Number of Family Members, 1987

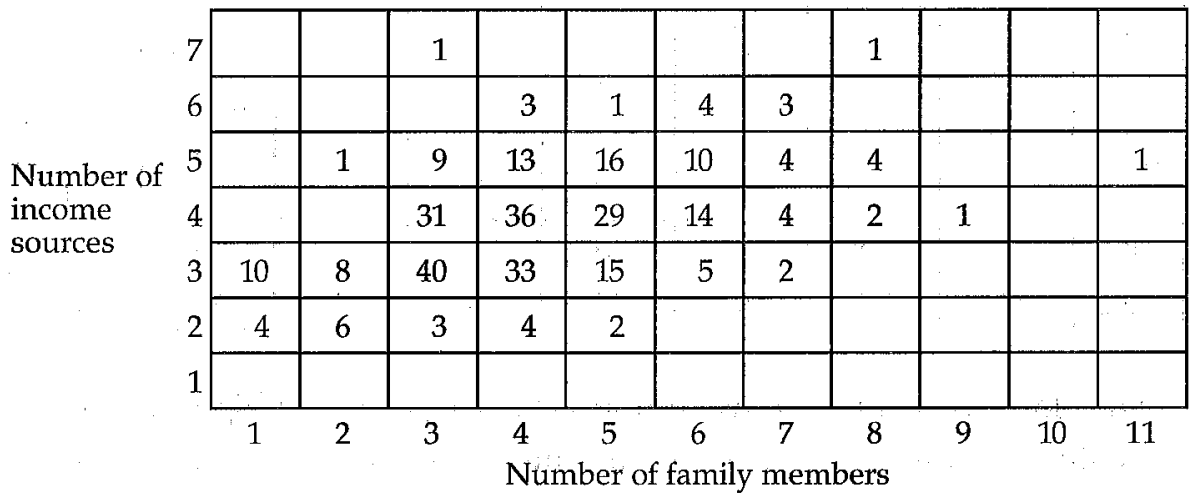

As the figure shows, each household has a variety of income sources. All households have crop production, raise pigs and engage in other occupations. The existence of rural surplus labour and past experience of rural famine are clearly reflected in the dominating family strategy of reproduction: Risk-minimizing by never abandoning basic food production and by insisting on several income sources.

The fact of (many) different incomesources in each household does not effect any greater income equality. This is due to the uneven distribution of »qualifications « (physical strength, education and technical skills, political influence and guanxi, etc.) and uneven relations of production (increasingly more household-run enterprises develop with employed labour). 


\section{Income Inequality in Crop Production}

The very limited inequality in cropproduction is due to the basic principles for distribution of land. When land is contracted to the households by the village committee, attention is paid to three main principles of land distribution:

1. Equal distribution according to number of household members.

2. Standardization of the $m u$, so that good, ordinary and bad soils are shared equally among the households. ${ }^{5}$

3. The distributed plots shall, preferably, be near the household.

Hence each household held several plots. Because of the scarcity of land several plots could not be reached within less than 15-20 minutes. Once a year the number of $m u$ was adjusted according to changes in number of household members. This has ensured that a very limited inequality of land per person existed among 300 of the 320 households ( 20 households had atypically small or large per capita land holdings due to a changing number of family members during the year, see below). The equal distribution of land is of course the very reason for the equal distribution of crop incomes.

The small differencies in crop incomes derive from:

- unequal endowment of physical strength and management ability.

- differencies in economies of "scale «: the large-sized households of maybe 7 members are more capable of and willing to undertake productive investments than a household of 2 members.

- a changing number of family members shortly after the yearly re-distribution of land (in the case of death or the marriage of a daughter) will increase the per capita size of land and per capita income of crop production.

- the equal land distribution is organized and regulated in each of the 5 village-groups. Hence the demographic changes that occur from year to year in the village groups result in minor, unequal land distribution per capita.

The above mentioned inequality factors, however, do not produce any significant inequality. The large majority of households earn about 420 Yuan per $m u$. A mere $20 \%$ inequality in crop-income per capita was found 
between group 1 and 10 . This was caused mainly by the unequal per capita size of land between village groups and the unequal endowment of physical strength and especially management ability.

\section{Income Inequality in Animal Husbandry}

Animal husbandry includes rearing of pigs and poultry with pig rearing as the most important source of income (90\%). This household-activity is primarily the responsibility of women and children.

Pig rearing greatly affects the income inequality in Xin Cun. The number of pigs increases from 0.86 pig per person in group 1 to 1.87 pig per person in group 10.

The average per capita income from pig-rearing increases from 182 Yuan in the poorest group to as much as 514 Yuan in the richest group. Thus the number of pigs per person shows a 2.17-fold increase between group 1 and 10 , but the corresponding income increase is 2.83-fold.

The income inequality from animal husbandry can be explained by:

- the households with a small number of pigs use a comparatively higher share for their own consumption, thus they market and earn relatively less than the households with larger stocks.

- the substantial benefits to be gained from pig rearing on a large-scale require: substantial investments in purchasing fodder, building sheds, and perhaps buying special breeding-stocks.

These factors did in particular benefit the upper-middle income groups 6, 7 and 8, where animal husbandry was found to be the main income. However, in the income groups 4, 5 and 9 pig rearing proved an important source of income. Of the factors causing income inequality the large-scale benefits (which required family-savings for investments) were the most crucial. To some extent guanxi was of importance in purchasing fodder and securing information needed from the extension service.

\section{Income Inequality in Non-farm Activities}

The non-farm activities include manufacturing industry, trade \& commerce, service, construction, transportation and other incomes (incomes from soldiers and villagers labouring in Chengdu). 
The distribution of non-farm income is the most unequal. Twenty poor families ( $6 \%$ of total) had no such income. Among the remaining 300 families the non-farm incomes ranged from a few Yuan to several thousand per capita. High incomes are concentrated in group 9 and 10.

Relatively low incomes are found in service, construction and, not surprisingly, other incomes. The very high incomes of group 9 and 10 are found in transportation, trade \& commerce and manufacturing industry. $42 \%$ of all non-farm incomes are concentrated in the richest tenth. The unequal distribution of non-farm incomes is due to:

- the large households' greater labour-force to engage in non-farm activities. The richest $5 \%$ of households on average had 4.6 members, while the poorest $5 \%$ had 3.4 members.

- differencies in qualifications: The lowest incomes (group one to eight) typically reflect the low degree of skills required, hence the competition is rather tough and incomes subsequently lower. Migrant workers are mostly engaged in construction as unskilled labourers (their remittances categorized as "other incomes»), which is also valid for most construction workers in Xin Cun. The relatively low incomes in service also reflect the simple qualifications needed in managing the petty-repair shops, etc. In contrast the very high incomes in transportation are due to the requirement of special skills, first of all a drivers license. Very few people, mostly previous drivers in collective enterprises, have such. Most manufacturing industries require technical skills in operating the more advanced and mechanized productions.

- differencies in scale: Few management qualifications are needed in the low-income branch of service and the petty-trade activities in commerce, which are typically single-person activities. Also, few investments are required in these low-technological and labour-intensive branches. In comparison the high-income activities in industry are characterized by their more advanced large-scale productions requiring management skills in term of planning and book-keeping. And the investments are sizeable. This was the case for a brick factory with 104 workers, a nut and screw factory with 58 workers, a textile factory with 40 workers, a factory (made up by 30 cooperants) producing prefabricated concrete elements, etc. 
- differencies in ownership relations: Some enterprises are collectively owned, others are privately owned with employed labour. ${ }^{6}$ If employed on a seasonal basis the daily labour income approximated 2-3 Yuan, while a full time employee earns about 500 to 1400 Yuan a year. In contrast, most owners of private enterprises, employing wage labour, scored an income of several thousand Yuan a year. The extra income from collective enterprises amounted to a few Yuan to each villager per year, only.

The unequal distribution of non-farm incomes is especially caused by different ownership relations. Of the 92 households engaged in industry and 79 households engaged in building construction the large majority were labourers and few were private enterprise owners. Two private sausage factories did, e.g. during the season (May-September), employ more than one hundred workers. Though the differencies in wage between private enterprise owner and employee was large, the employees often earned a higher income than the few labourers in collective enterprises.

Qualifications also proved an important factor in explaining the income differences. It was found that these two factors were closely interlinked. The people owning private enterprises also possessed the required qualifications. Furthermore it was found that qualifications, defined as technical and management skills, were inadequate. The private enterpreneurs were rather characterized by another requirement: Close personal relations (guanxi) to the local authorities. This ensured favourable treatment in obtaining rationed goods, official permits, political good-will, etc., which proved of significant importance when developing a profitable business in risky, bureaucratic settings. Guanxi was the most important requirement.

\section{Limits of Future Income Growth}

The qualifications or requirements in developing non-farm activities merit further attention, since future income growth seems to depend largely on such activities. The potentials for prolonging the productivity growth in cropproduction and to a certain extent in animal husbandry are limited. The upper limit for crop productivity seems to be within close reach. Wenjiang already in 1983 had the 11th highest grain yield per unit cultivated land of the 2080 counties in China. ${ }^{7}$ With plot sizes only half of the aver- 
age in China, an intensive cultivation of hybrid grain varieties, an excessive use of fertilizers, a well-functioning irrigation scheme, few benefits to be gained from a large-scale economy due to the well-functioning collective infrastructure and labour-intensive cultivation making investments in farm machinery less relevant, the over-all prospects for higher yields are limited indeed. This was confirmed by the local extension service. In comparison to the general situation in rural China, the investment in irrigation, etc. was higher than average, and higher state-purchasing prices for grain would not increase the output much. Consequently the local extension officers had shifted their attention to the effort of reducing the widespread fertilizer pollution and promoting the development of sideline productions into specialized productions.

Also, certain limits for pig rearing as a sideline activity seem to be within reach. The number of slaugthered pigs per capita in Wenjiang was the 15 th highest of the 2080 counties in $1983 .{ }^{8}$ Even if the typical household has fewer pigs than the average figure indicates, due to the emerging highly productive specialized households, the potential for raising more pigs as a sideline activity is to some extent limited. Only specialized households seem to be able to develop pig rearing further. However other types of animal husbandry, e.g. raising chicken or ducks, may be a future opportunity for the average household - but that would require a shift in diet and market demand.

The relative importance of crop production and pig rearing can be illustrated by the fact, that although their income contribution rank among the very top in China, Wenjiang's average rural per capita income »only « ranks number 452 of the 2015 counties in $1986 .^{9}$

So, besides specialized pig-rearing households, the economy largely depends on the further growth of the non-farm activities. This may well have substantial implications for the income distribution, since the non-farm incomes were the most unequal due to the required skills, investments, guanxi, etc. This situation can be forecasted as typical for the future Chinese agriculture. Xin Cun's land scarcity and many pigs per family constitute important limits to growth that most localities in rural China may face in the future. Thus Xin Cun in some respects may indicate the future prospects for a lot of rural areas in China. This highlights the relevance of focusing on the new, emerging sources of income in Xin Cun. 


\section{Conceptualizing the New Income Distributional Trends}

The new important income sources are industry, transport, commerce and construction, or specialized agriculture. The collective enterprises in Xin Cun did not supply the jobs needed. The effort of local authorities had been too insufficient, it was voiced. Instead it was the future task of the family-based individual and joint enterprises to develop these activities. This situation parallels the general situation in China, where a rapidly growing number of household-based enterprises now promotes the boom of new rural enterprises. ${ }^{10}$

As the presented Xin Cun data have shown, it is in these occupations the high incomes are concentrated. When considering the limited straditional " growth potentials, surprisingly few people have taken up these specialized occupations. An important explanation is the lack of required qualifications needed. This may have quite important effects on the longterm development of the social structure. In order to conceptualize this, Marc Blecher focuses on the interrelationsship between income distribution and unequal qualifications: ${ }^{11}$

Socialist inequality: derives from an unequal endowment of talents, skills, physical strength and other human innate capabilities.

Capitalist inequality: does, in addition to the human inequalities, derive from unequal ownership of physical means of production other than labour (e.g. land, financial capital, technology).

Though Blecher's approach is somewhat problematic - e.g. the non-innate human capabilities formed by the social environment are not categorized - we are not going to discuss it as such. For our present purpose it is sufficient to use the main content in Blecher's approach in assessing the emerging income inequalities.

The moderate income inequality of crop production and to a certain extent pig-rearing as sideline production seems to result mainly from unequal human capabilities. But the as yet highly concentrated high-income occupations of specialized pig-rearing and private enterprises do to a much larger extent depend on privately owned means of productions - or capitalist inequalities. However, in Blecher's view, this does not indicate that these emerging activities will transform China to a capitalist society. Thus capitalist patterns of inequality may function to enforce the creation 
of the material basis for socialism. The development of a more socialized production and a higher level of means of production can as such shorten the transitional phase to socialism. ${ }^{12}$ This does, however, require an institutional control of the market conditions, and an active popular control of the political institutions. ${ }^{13}$

Widespread tax-evasion, corruption and black labour markets have in other rural areas been used as examples of actual loss of state control. Some have interpreted this as an indication of a rising capitalism. ${ }^{14}$ Our field study did not justify such conclusions. It did not indicate a loss of state control - rather the emergence of a strong state beyond popular control. Seemingly close ties were forged between the state and the rich specialized households in enterprises and agriculture. As shown in the field-study, guanxi and network relations to the local authorities constituted an important requirement for the high-income groups. It is these households, which in Blecher's view represent a capitalist inequality. However, we think that Blecher's approach here does neglect the importance of the symbiotic relations between the local state and these specialized households.

With the rural reforms the household has once more become the basic economic and social unit. The importance of kinship ties and patron-client relationships has been re-strenghtend. ${ }^{15}$ In some cases, marriage was considered a means to unite economic wealth and to secure upward mobility by extending the family. ${ }^{16}$ Informal network-relations are on the rise to protect and take care of the interests of rich specialized households.

This is only furthered by the local cadre-elections, in which the economic elite integrates with the political elite. It is the most succesful villagers, who are elected, because they are considered the best qualified to guide the rest ahead to prosperity. Hence, the Xin Cun village leader predicted that he would not be re-elected, since many villagers were dissatisfied with the lack of instructions on how to promote the development of household enterprises. This was stated as their major concern electing village leaders. An indication of this is the number of cadres belonging to specialized households: 5 of 17 Xin Cun cadres were from specialized households. In Jinma township, as a whole, the figure was as high as $40 \%$.

This brings into focus the formation of powerful local alliances. In many other rural areas the cadres have favoured family members in granting loans and permissions, in distributing rationed goods and inputs, etc. Hence, the integration of the local economic and political elite ${ }^{17}$ indicates 
another type of inequality different from both the socialist and capitalist type of inequality. In our opinion Blecher's two types of inequality must be extended with a third type:

Bureaucratic inequality: deriving from unequal endowments of means of influence on the state apparatus. An unequal allocation of finance, capital, labour, permissions, and unequal political treatment, etc. also form patterns of income inequality.

We do not hereby claim the existence of - or engage in the discussion of - a so-called »Bureaucratic mode of production « or similar concepts. We simply suggest that the general scarcity of goods and inputs combined with the market restrictions as well as the limitations of popular institutional control necessitate the concept of another type of inequality. Therefore differencies in political skills, bureaucratic network relations, and guanxi tend to be an equally important distributional factor as the first two mentioned above.

The current institutional reforms are probably not a secluded attempt to increase the level of administrative skills - they could also be viewed as an attempt to reduce the integration of power and corruptive abuses. ${ }^{18}$ The plans to establish a separate corps of professional administrators to take over parts of the administration from the political cadres is also noteworthy. The local power struggle has, if not in Xin Cun then in many Chinese rural localities, entered a new phase. Informal network structures, guanxi, corruption, tax-evasion, black markets, etc. could indicate grave difficulties in controlling bureaucratic or capitalist inequalities. The current political reforms, the emerging detailed legal regulations, ${ }^{19}$ the tax reforms, and the increased land-use control ${ }^{20}$ could indicate a more tough stand in order to control the non-socialist inequalities.

In sum, a diversified and complex inequality pattern is developing in the Chinese countryside. The non-farm activities have substantiated grave income inequalities spearheaded by the private enterprises and specialized households. The inequality reflects not only requirements needed in terms of skills and capital, etc., but also requirements in terms of guanxi and network relations to local authorities. As alleged in this article, the rural inequalities cannot be understood without employing the concept of a bureaucratic type of inequality interacting with the other types of inequality. 
Ole Odgaard is a Research Fellow at the Center for East and Southeast Asian Studies, University of Copenhagen. Steen Folke is Associate Professor at the Institute of Geography, University of Copenhagen. Peter Fenger, Allan Jørgensen and Peter Milthers are post-graduate students at the Institute of Geography, University of Copenhagen. The article is based on a stay in Xin Cun village in Sichuan, in which additional 10 post-graduate students from the Department of Geography, University of Copenhagen participated.

\section{NOTES:}

1 Zhongguo Tongii Nianjian - 1988 (Beijing: Zhongguo Tongji Chubanshe, 1988), p. $211+214$.

2 Zhongguo Tongji Zhaiyao - 1988 (Beijing: Zhongguo Tongji Chubanshe, 1988), p. $21+29$.

3 According to our Chinese source, payments contain various expenses such as agricultural tax, irrigation fee, public welfare, purchased inputs (especially for pig-rearing), etc. The total public payments amount to one-fourth of the gross-income, approximately.

4 The main income is the largest single source of gross- income.

5 Thus $1.4 \mathrm{mu}$ of the rather sandy soil by the river was equalized to, i.e., 1 standard $m u$.

6 The term "private enterprises here covers the official term of $*$ individual enterprises « (employs 7 or less workers, called "geti qiye»), "private enterprises (employs more than 7 workers, called »siying qiye») and «joint enterprises« by several households (called "lianhu qiye»). No distinction will be made between these three types of household-based enterprises.

7 Zhongguo Nongye Nianjian - 1984 (Beijing: Nongye Chubanshe, 1984), p. 432.

8 Zhongguo Nongye Nianjian - 1984 (beijing: Nongye Chubanshe, 1984), p. 438.

9 Zhongguo Nongmuyuye Tongji Ziliao 1986 (Beijing: Nongye Chubanshe, 1987), p. 230.
10 Ole Odgaard, »The Succes of Rural Enterprises in China: Some Notes on Its Social and Economic Effects, "China Information, Vol. III, No. 2 (Autum 1988, pp.63-66 and 75-76.

11 Marc Blecher, »Inequality and Socialism in Rural China: A Conceptual Note, « World Development Vol. 13, No. 1, 1985 , p. 116. For a more thorough theoretical discussion, see John Roemer, $A$ General Theory of Exploitation and Class (Cambridge, Mass.: Harvard University Press, 1982). For a discussion of the productive relations, see Marc Blecher's article: "The Structure and Contradictions of Productive Relations in Socialist Agrarian 'Reform': A Framework for Analysis and the Chinese Case, "The Journal of Development Studies, Vol. 22, No. 1, October 1985, pp. 104-126.

12 Blecher, "Inequality and Socialism in Rural China," p. 117.

13 See Victor Lippit, "Socialist Development in China, " Mark Selden \& Victor Lippit, Eds., The Transition to Socialism in China (New York: Armonk, 1982), p. 123 and 132-36.

14 See f.ex. William Hinton, "Whither China's Agricultural Reforms?, Contemporary Marxism, No. 12-13, 1986, pp. 137-143.

15 For a general description, see Jean C. $\mathrm{Oi}$, "Communism and Clientelism," World Politics, Vol. 37, No. 2 (January 
1985), pp. 238-266.

16 For a general description, see Elizabeth Croll, "New Peasants Family Forms in Rural China, « Journal of Peasant Studies, Vol. 14, No. 4 - July 1988,pp. 485- 496.

17 See Gordon White's description of such complex social formations, which in type are different from both a capitalist and socialist society. Gordon White, »The Impact of Economic Reforms in the Chinese Countryside Towards the Politics of Social Capitalism?, «Modern China, Vol 13, No. 4, (October 1987), pp. 411-440. For an analysis of the commercialized rural cadres, see Jean C. Oi, „Commercializing China's Rural Cadres, " Problems of Communism, Vol. 35, (September-October 1986), pp.1-15.

18 See Ole Odgaard, "Agricultural Crisis in China: The Failed Decentralization, "
Copenhagen Discussion Paper, No. 11 (February 1990), pp. 28-32.

19 For industrial and commercial household enterprises, see Renmin Ribao August 19, 1987 and June 29, 1988; Zhonghua Renmin Gongheguo Guowuyuan Gongbao, August 8, 1987, No. 20, pp. 670-74; Zhonghua Renmin Gongheguo Guowyyuan Gongbao, October 15, 1987, No. 24, pp. 805-810; and Beijing Review, March 6-12, 1989, Vol. 32, No. 10, pp. IX-XVI.

20 Flemming Christiansen, "An Analysis of Recent Developments in China's Land Registration: Some New Trends in Chinese Land-Ownership and Land-use, "China Information, Vol. I, No. 3, (Winter 1986-87), pp. 27-28. The Land Administration Law is, though, still inadequate, because the responsibility for infringements is not defined. 